\title{
Chapter 18 \\ Guiding Urban Facilities and Functions in Compact Mixed-Use Development from the Perspective of Residents
}

\author{
Toru Ishikawa
}

\begin{abstract}
This article discusses the development of compact and functionally integrated urban environments from the perspective of local residents, focusing on their psychological evaluations of mixed land use and performance-based regulation. It demonstrates the significance of residents' perceptions and attitudes in the achievement of flexibility required for urban planning in a shrinking society. To promote planned concentration of various functions in an urban area in an appropriate way, as in the development of compact cities in a multi-polar network advocated by the Location Normalization Plan, it will have more importance than ever to conceive planning that takes the characteristics of both a region and its residents into account.
\end{abstract}

Keywords Residential environments · Psychological evaluation · City shrinkage · Resident adaptive planning $\cdot$ Performance-based regulation

\subsection{City Shrinkage and Integration of Urban Functions}

In Japan, a rapid decrease in the population due to a low birth rate and aging society has caused many societal problems, including a declining labor force rate, increased social security costs, and the difficulties of maintaining infrastructures. The aging population poses problems for urban planning as well, and the government tackles problems associated with urban shrinkage through the provision of compact residential environments, in a policy framework of location normalization planning.

Notably, the decreasing population brings about an increase in vacant properties and unused land lots, which leads to a decrease in the pressure of urban development. This means that the existing approach to urban planning, which is based on the idea of controlling the expansion of urban areas and regulating excessive development, may not work in a shrinking society. In response to a call for a new planning

\footnotetext{
T. Ishikawa $(\bowtie)$

INIAD Toyo University, Tokyo, Japan

e-mail: toru.ishikawa@iniad.org

Y. Asami et al. (eds.), Frontiers of Real Estate Science in Japan, New Frontiers in 
method, therefore, Japan's Urban Renaissance Special Measures Law advocates the concepts of "compact city planning" and "networks with public transportations," with an aim to promote the construction of compact urban areas through flexible planning that takes into account the situations and characteristics of target areas.

The development of compact urban areas, importantly, entails concentration of different urban functions in a planned and guided manner, since the concept of compact cities is based on the goal of locating various urban facilities and services within walking distance. The construction of such a planned mixed-use residential environment, however, is difficult to achieve by the existing planning method, because it intends to protect the uniformity of land use in residential environments and guarantee minimum standards of living by predetermined, omnibus regulation. That is, the systematic mixing of different land uses and concentration of urban functions does not conform to the traditional approach to planning that sets residential, commercial, or industrial areas and restricts the types of land uses permissible in each area. To respond to the requirement of flexible land use planning, a new method called performance-based regulation has been proposed, which defines technical standards for the protection of residential quality through the evaluation of performances of urban facilities (i.e., regulating the conditions of facilities that may affect surrounding environments) (National Institute for Land and Infrastructure Management 2008; Special issue of Urban Housing Sciences 2016).

What, then, is an "appropriate" degree of integration of different urban functions or an "optimal" level of compactness of an urban area? Performance-based regulation flexibly approves the construction of urban facilities that are not permissible in light of current land use zoning, provided that the facilities fulfill certain requirements that ensure their performances. But, now, how can the "fulfillment of certain requirements" be objectively judged and evaluated?

Past studies discussed compact cities in terms of locational accessibility to facilities and a cost-benefit analysis of infrastructure maintenance. When the development of compact cities and the guidance of various urban functions within residential areas are to be conducted in a flexible and performance-based manner, the perspective of local residents becomes important, namely the consideration of residents' perceptions and attitudes with regard to the integration of city functions and the mixing of different land uses (Policy Research Institute for Land, Infrastructure, Transport and Tourism 2010).

Generally speaking, residents want to protect their residential environments but also seek for the improvement of convenience of life. To what extent do residents accept the existence of different services in the vicinity; or how do they evaluate various facilities and psychologically trade-off the protection of residential environments and the improvement of convenience? When undesirable facilities are to be developed nearby in their residential environments, do residents approve the development if the degree of influence (usually negative) on the surrounding environments is properly controlled? In essence, how do residents psychologically assess and evaluate their residential environments?

With these practical and theoretical issues in mind, this article overviews the existing research on the development of compact and functionally integrated urban 
environments in a shrinking society from the perspective of residents, focusing on their psychological evaluations of mixed-use development and perceptions of performance-based regulations.

\subsection{Consideration of Urban Functional Integration from the Perspective of Residents}

\subsubsection{Evaluation of Residential Environments by Residents}

First, we look at the concept of "residential satisfaction," which is a widely used term and of particular importance for an understanding of residential environments from the perspective of residents. Ishikawa and Asami (2012) examined the structure of psychological evaluation of residential environments by analyzing the relationship between residential attributes, personal values, and physical environments. A survey questionnaire was administered to 9423 residents in Tokyo and Kashiwa City, asking about their residences, residential environments, criterions for housing selection, and evaluations of their residential environments from various viewpoints, such as environmental quality or convenience.

An analysis of the residents' responses through a factor analysis and structural equation modeling yielded a model of psychological evaluation shown in Fig. 18.1, which consists of 13 factors: (1) family-type residence; (2) household members; (3) long-term residence; (4) priority given to educational environments; (5) traditional values; (6) satisfaction with residential environments; (7) satisfaction with convenience; (8) satisfaction with educational environments; (9) satisfaction with security and safety; (10) satisfaction with the public image of residential areas; (11) high-density, commercial (non-residential) districts; (12) agricultural districts; and (13) industrial districts.

The factor "traditional family-type residence" concerned residential attributes, which was defined by home ownership, residence in a detached house, a large house size, participation in community activities, knowledge of land use zoning, living with a spouse or unmarried children, and a high income.

Residential satisfaction was divided into five components, each relating to residential attributes and physical environments differently. For example, family-type residents tended to live in residential (non-commercial) and agricultural districts for a longer time, and have a higher degree of satisfaction with regard to security and safety, residential environments, and educational environments. Residents in commercial districts tended to be satisfied with convenience, whereas residents in residential districts tended to be satisfied with security and safety and residential environments.

Notably, the level of residential satisfaction was affected by individuals' personal values to a greater degree than by other factors. Residents who scored higher on traditional and altruistic values tended to have a higher degree of residential 


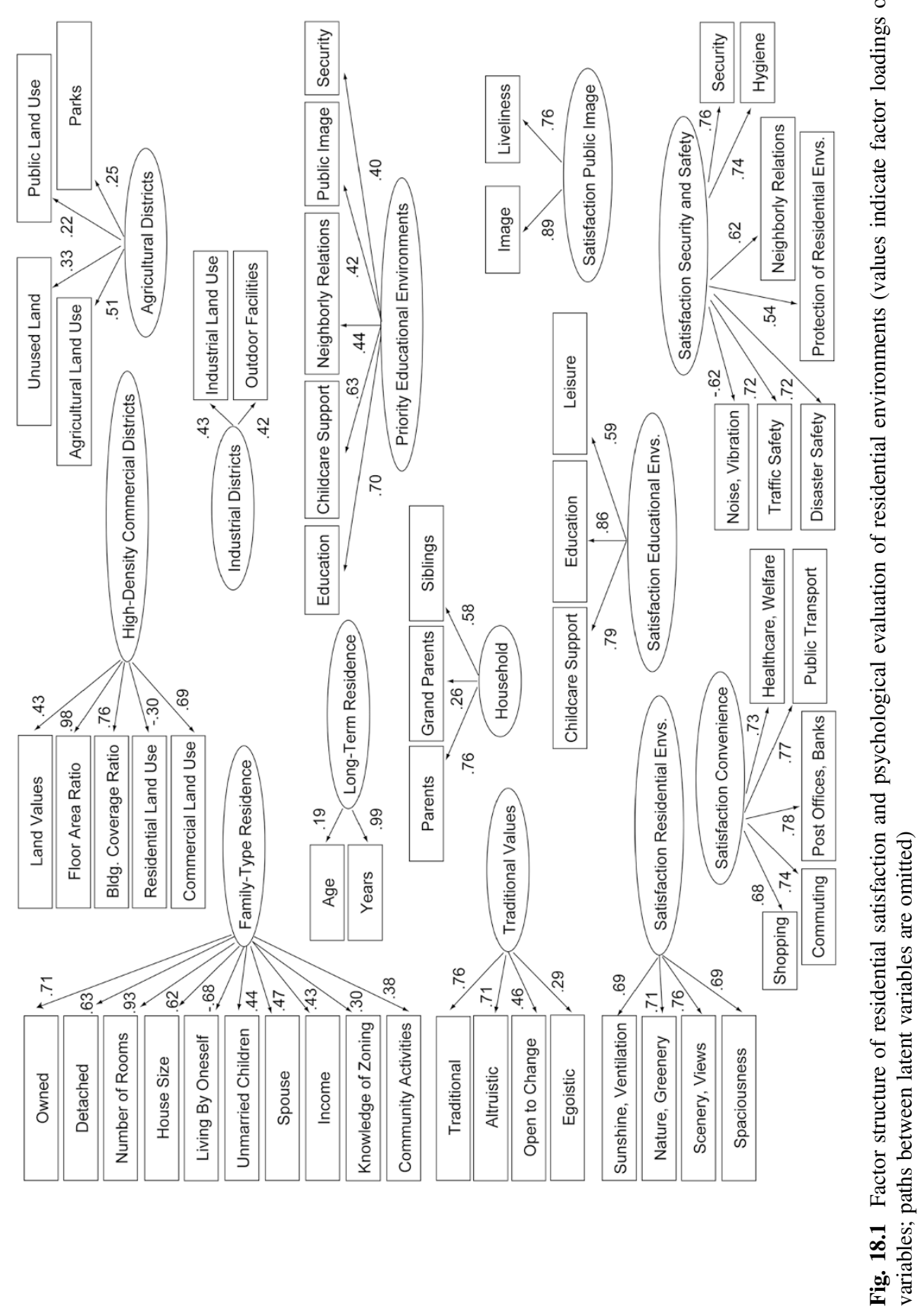


satisfaction overall and wanted to continue to live in their current residential neighborhoods.

\subsubsection{Attitudes to Mixed Land Use and the Effect of Performance-Based Regulation}

Next, we look at residents' perceptions and awareness of mixed land use and attitudes to the concentration of urban functions in the development of compact cities. Ishikawa and Asami (2013a) administered a questionnaire to 2993 residents nationwide and examined their psychological evaluations of various urban facilities and services in residential areas.

Respondents were given a list of 26 major urban facilities and asked to evaluate, on a 7-point scale, whether they would like each facility to be located in their residential environments $(1=$ do not like it located; $7=$ like it located $)$. Results in Table 18.1 show that residents wanted to have parks, shopping streets, convenience stores, and hospitals to be located nearby (a mean score of 5.5 on a 7-point scale), but did not want short-term rental apartments, garbage disposal facilities, warehouses, and sports facilities to be located nearby (a mean score of 2.5).

Respondents also described why they did not want specific facilities to be located nearby. Their answers showed some systematic patterns; in particular, many residents were concerned about noise and passers-by caused by the existence of facilities that they thought undesirable. Noise and passers-by were also given by some residents as reasons why they did not like facilities such as parks, shopping streets, and convenience stores to be located nearby, although these facilities were generally regarded as favorable.

A possible effect of improving the performances of facilities by regulating the quality that residents identified as reasons why they disliked those facilities (whose mean evaluation scores were below 2 on a 7-point scale) was further examined by

Table 18.1 Evaluation scores of various facilities (on a 7-point scale), reasons why the facilities were undesirable (percentage of responses for noise and passers-by), and the effect of improving their performances

\begin{tabular}{l|l|l|l|l}
\hline Facility & Evaluation & Noise & Passer-by & Effect size \\
\hline Park & 5.8 & 48 & 38 & 3.2 \\
\hline Shopping street & 5.5 & 44 & 48 & 3.3 \\
\hline Convenience store & 5.5 & 39 & 53 & 2.2 \\
\hline Short-term apt. & 2.8 & 12 & 68 & 1.7 \\
\hline Garbage disposal & 2.4 & 41 & 5 & 1.4 \\
\hline Hospital & 5.5 & 24 & 41 & 3.1 \\
\hline Parking lot & 4.6 & 60 & 31 & 1.5 \\
\hline Warehouse & 2.4 & 58 & 23 & 1.3 \\
\hline Amusement & 2.9 & 49 & 59 & 1.5 \\
\hline
\end{tabular}


asking, "If the reason that you do not want the facility to be located nearby is controlled (e.g., the level of noise is reduced), would you want it to be located nearby?" The effect size of improvement was examined in terms of the difference in evaluation scores before and after the supposed improvement, divided by a former standard deviation (Table 18.1). Results revealed a significant increase in evaluation for parks, shopping streets, and hospitals (a mean effect size of 3.2), but not for garbage disposal facilities, parking lots, warehouses, and sports facilities (a mean effect size of 1.5).

These findings point to the possibility that facilities in the former group may be accepted for inclusion in residential environments with appropriate regulation of annoying factors. For facilities in the latter group, however, controlling of their performances through regulation does not contribute much to the improvement of residents' psychological evaluations.

\subsubsection{Evaluation of Life Convenience and Tolerance to Land Use Mix}

Finally, we look, in relation to the preceding findings about residential satisfaction and attitudes to mixed land use, at the connection between the degrees of satisfaction with convenience and tolerance to land use mix. Ishikawa and Asami (2013b) examined tolerance to, or psychological acceptance of, mixed land use among 1259 residents in Tokyo and Kashiwa City, through a questionnaire survey asking about the distance to travel to various facilities and the level of satisfaction with these travel behaviors.

An analysis of their responses through structural equation modeling yielded a path model shown in Fig. 18.2. It illustrates the relationship of the distance to a facility and satisfaction with travel (path 1) and the relationship of satisfaction with travel, priority given to residential environments and life convenience, traditional values, and residence in commercial with the degree of tolerance to the mixture of non-residential facilities in residential areas (paths 2-6).

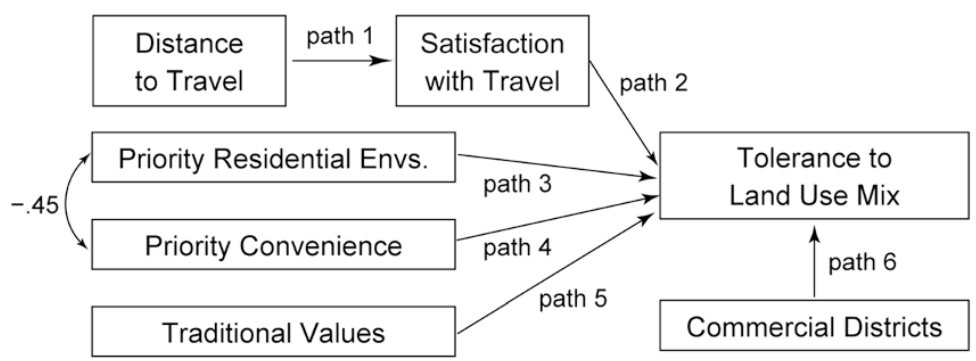

Fig. 18.2 Structural equation model of satisfaction with travel and tolerance to land use mix 
Table 18.2 Path coefficients for the structural equation model of satisfaction with travel and tolerance to land use mix (ns: nonsignificant)

\begin{tabular}{l|l|l|l|l|l|l|l}
\hline Activity & Facility & Path 1 & Path 2 & Path 3 & Path 4 & Path 5 & Path 6 \\
\hline Hospital & Hospital & -0.29 & 0.12 & ns & ns & 0.20 & ns \\
\hline Shopping & Shopping street & -0.18 & ns & ns & ns & 0.19 & 0.10 \\
\hline & Shopping mall & -0.18 & ns & ns & 0.11 & ns & ns \\
\hline & Convenience store & -0.18 & 0.12 & ns & 0.10 & ns & 0.09 \\
\hline Walking & Park & -0.14 & ns & -0.09 & ns & 0.23 & ns \\
\hline
\end{tabular}

Among the combinations of the types of activities and facilities examined in the Ishikawa and Asami (2013b) study, this article focuses on (a) visits to hospital, (b) shopping for daily necessities in a shopping street, (c) shopping for daily necessities in a large shopping mall, (d) shopping for daily necessities at a convenience store, and (e) taking a walk in the park (Table 18.2).

The coefficients observed for path 1 were negative, showing that the level of satisfaction with travel tended to be higher as the distance to travel became shorter. However, satisfaction with travel was not related to the degree of tolerance to land use mix (path 2 coefficients were small or nonsignificant). That is, although the level of satisfaction decreased with increased distance to travel to visit associated facilities, people who were dissatisfied with travel did not want the facilities to be located nearby in their residential areas. In other words, dissatisfaction with convenience in terms of traveling does not necessarily lead to the acceptance of non-residential facilities by local residents in the form of mixed land use. It was also found that personal values of individual respondents (traditional values) tended to influence their tolerance to mixed land use (path 5), pointing to the importance of considering the characteristics or attributes of residents.

\subsection{Toward the Guidance of Urban Facilities and Functions Adapted to the Characteristics of Regions and Residents}

This article discussed how urban planning can tackle problems associated with city shrinkage through the development of compact cities, and particularly how an appropriate level of integration of different urban functions can be achieved with the attributes of local residents and their perceptions of, and psychological tolerance to, land use mix taken into consideration.

First, the concept of residential satisfaction was decomposed into five categories (satisfaction with residential environments, convenience, educational environments, security and safety, and a public image), and the relationship between each type of satisfaction and residential and physical environmental attributes was examined. In the evaluation of residential environments by residents, personal values were shown to have significant effects. 
Next, an analysis of local residents' perceptions of land use mix showed that there are urban facilities and functions that many residents want to be located in the vicinity (parks, shopping streets, convenience stores, and hospitals) and facilities that they do not want to be located (short-term rental apartments, garbage disposal facilities, warehouses, and sports facilities). There was also a systematic pattern in the reasons that residents did not want specific facilities to be located nearby, annoyance due to noise and passers-by being a major reason. Furthermore, controlling and eliminating the reasons for the annoyance was found to improve the tolerance to the existence of parks, shopping streets, and hospitals. These results indicate the possibility of promoting the mixture of these land uses in residential areas with performance-based regulations, and suggest the significance of taking residents' perceptions and attitudes into account in the practice of flexible urban planning.

A further analysis of the relationship between satisfaction with travel and tolerance to land use mix showed that although residents tend to be dissatisfied if the distance to travel to engage in activities at specific facilities is longer, they do not necessarily want those facilities to be located nearby (i.e., oppose to mixed land use in residential areas). Stated differently, promoting compact urban development and integration of different urban functions solely from the viewpoint of improving life convenience may cause psychological resistance from local residents.

What are the implications of these results for the practice of guiding urban functions in the planning of compact urban environments? Importantly, it should be stressed that there is a close relationship between psychological evaluation of residential environments and physical environmental attributes. When approaches to urban planning aim to deal with problems due to city shrinkage flexibly, they are required to adapt to the characteristics of regions and residents (i.e., locality and people), as opposed to traditional planning approaches that are based on predetermined and omnibus regulations.

In particular, this article demonstrates the significance of residents' perceptions and attitudes as a main target in the consideration of this sort of flexibility in urban planning for a shrinking society. To promote the guidance and concentration of functions in urban areas appropriately and effectively with a view to developing compact cities with multi-polar networks, as advocated by the Location Normalization Plan, it will be more important than ever to conceive planning that emphasizes both the region and the resident.

To achieve the goals of guiding urban facilities and functions in a manner tailored to regions and maintaining residential environments with due consideration of local residents is in general not straightforward. But considering the diversity of urban functions, residential preferences, and lifestyles in our present and future society, new approaches in planning that assume flexibility with respect to local situations and residents are essential. To that end, studies of residential environments from the perspective of residents, as discussed in this article, will become still more important. 


\section{References}

Ishikawa T, Asami Y (2012) Perception of the quality of urban living and residential satisfaction: in relation to residential characteristics, human values, and physical environments. J City Plan Inst Jpn 47(3):811-816

Ishikawa T, Asami Y (2013a) Urban residents' perception and evaluation of land-use and dimensional regulations: effects of reducing unpleasant factors and the possibility of performancebased regulation. J City Plan Inst Jpn 48(1):1-8

Ishikawa T, Asami Y (2013b) Residents' psychological evaluation of mixed land use in residential areas. J City Plan Inst Jpn 48(3):909-914

National Institute for Land and Infrastructure Management (2008) Basic study toward making performance-based standards on dimensional code of buildings. Technical Note of National Institute for Land and Infrastructure Management, No. 443

Policy Research Institute for Land, Infrastructure, Transport and Tourism (2010) Housing policies to promote social mix. PRILIT Research Report, No. 94

Special issue of Urban Housing Sciences (2016) Urban planning in the age of city shrinkage: a possibility of land use mix and performance-based regulation. Urban Housing Sci 95:3-53

Open Access This chapter is licensed under the terms of the Creative Commons Attribution 4.0 International License (http://creativecommons.org/licenses/by/4.0/), which permits use, sharing, adaptation, distribution and reproduction in any medium or format, as long as you give appropriate credit to the original author(s) and the source, provide a link to the Creative Commons licence and indicate if changes were made.

The images or other third party material in this chapter are included in the chapter's Creative Commons licence, unless indicated otherwise in a credit line to the material. If material is not included in the chapter's Creative Commons licence and your intended use is not permitted by statutory regulation or exceeds the permitted use, you will need to obtain permission directly from the copyright holder. 